[4] G. Bertrand and G. Brooks, ibid, 1,109(1934)。

[5] C. R. Dawson and S. V. Sunthankar, J. Am. Chem. Soc., 76, 5070(1954)。

\section{無机化合物硫酸釩以及氯化鉻 治疗流行性感置}

在以前的报告里 $[1]$ 証明了釷、鉻、銅、鍶、鑭、 釷、鉛、釷等元素（按原子序数排列）对流行性感冒 病毒有抑制作用。后来我們用了这些元素或者这些元 素的化合物治疗流行性感嘪。这里报告的是关于硫酸 釷和氮化鉻的試驗。

在第一个試驗里, 鼠 30 只, 随机分成三組, 每組 10 只, 使其感染甲型流感病瑇 $P R_{8}$ 。第一組为对照 組，第二組在感染以后立副从鼻孔滴注 $0.3 \%$ 的硫酸 釩 3 滴，抹从静脉注射硫酸釩 0.05 毫克。接着 4 天， 每天皮下注射硫酸釷 0.1 毫克，以后連續 9 天皮下注 射硫酸釚 0.02 毫克。第三組鼠处理方法与此类似，感 染以后，滴注 $0.3 \%$ 的氯化鉻 3 滴，靜脉注射氮化 鉻 0.8 毫克，接着 4 天每天皮下注射氯化鉻 1 毫克，以后 漸續 9 天皮下注射氯化鉻 2 毫克。表 1 及变异数分析 說明在肺部損伤平均程度方面，对照組与第二組（硫 醊釷）之間抹無显著差异，第三組（氯化鉻）与对照 組相比，差异十分显著。但是在平均存活日数方面， 第三組与对照組之間却沒有显著的差异。

在第二个試驗里，鼠 70 只随机分成 7 組，每組10 只，使其感染甲型流感病毒 $\mathrm{PR}_{8}$ ，然后以不同的分量 皮下注射硫酸釩或氯化鉻（表 2 ）。注射共延續 5 天， 由于毒性太大，然后必須停止。只有第 5 組又注射了 5 天，每天一次。表 2 及变异数分析說明在肺部 平均 損伤程度方面，第 3 組（硫酸釷 1 毫克）、第 4 組（硫 酸釩 2 毫克）和第 5 組（氯化鉻 1 毫克）与对照組相 比，有显著的差异。在平均存活日数的差异方面， 第 5 組（氯化鉻 1 毫克）与对照組有显著差异， $P<$ 0.001。因为硫酸釷是有毒的，第 4 組（硫酸釩 2 毫 克）的平均存活日数很少。我們解剖了 10 只鼠的户 体，墢現这些鼠全都心脏扩“张，腸里有粘液状內容物， 而且出血， 8 只鼠腹河，肝脏紅色，有 3 只鼠腎胜出 血。一般說来，用釩处理的鼠肺部水肿現象甚为輕微， 而对照組和用鉻处理的鼠有严重的水肿。靜脉注射硫 酸釩对鼠是有毒的。注射 1 毫克硫酸釷，就能立刻致 鼠于死命，注射硫酸釷 0.2 毫克，也有 $50 \%$ 的鼠被杀 死。相反地，氮化鉻抹無毒性，教脉注射 1 毫克仍能 忍受。

在第一个試驗里, 是一个很大的負相关, $r=-$ 1.001, 也就是說，肺部損伤越輕，存活日数越久。在
第二个試驗里 $r=-0.088 ， P>0.05$ ，不显著，肺部 損伤与存活日数各不相关。第 4 組相关程度很低，是 因为硫酸釷有毒，所以到了第二天鼠都死了，同时也 因为病毒的毒性强，对照組鼠的存活日数也只有 4.8 天。

从这两个試驗，我們可以得出这样的結論：硫酸 釩和氯化鉻有治疗流感的作用。硫酸釩有毒，但它有 好的作用，可以减輕肺脏的水肺。

中葋檳榔、橫芦、常山对流感也有疗效[2]，也可

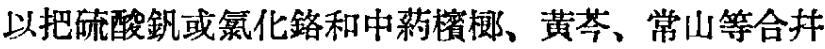
使用。这样合抹使用，可能比单独分开处理的效果好

表 1 感染甲型流感病荺 $\mathrm{PR}_{8}$ 的鼠, 茾經硫酸钢 $\left(\mathrm{VOSO}_{4}\right)$ 和柔化鉻 $\left(\mathrm{CrCl}_{3}\right)$ 处理

\begin{tabular}{|c|c|c|c|c|c|c|c|c|}
\hline \multirow{2}{*}{$\frac{\text { 对 }}{x}$} & \multicolumn{2}{|l|}{ 照 } & \multicolumn{3}{|c|}{ 硫 酸 釚 } & \multicolumn{3}{|c|}{ 氮 化 鉻 } \\
\hline & $\sqrt{x+0.5}$ & $T$ & $x$ & $\sqrt{x+0.5}$ & $T$ & $x$ & $\sqrt{x+0.5}$ & $T$ \\
\hline 3.5 & 2.00 & 2 & 2.5 & 1.73 & 2 & 3.5 & 2.00 & 3 \\
\hline 3.8 & 2.07 & 3 & 4.0 & 2.12 & 6 & 2.7 & 1.79 & 4 \\
\hline 4.0 & 12 & 5 & 3.8 & .07 & 6 & 3.9 & 2.10 & 6 \\
\hline 4.0 & 12 & 6 & 3.6 & .02 & 6 & 3.9 & 2.10 & 6 \\
\hline 4.0 & 12 & 6 & 3.9 & 10 & 7 & 3.8 & 2.07 & 7 \\
\hline 3.8 & 2.07 & 6 & 3.3 & 1.95 & 7 & 3.6 & 2.02 & 9 \\
\hline 3.8 & 2.07 & 6 & 3.9 & 2.10 & 7 & $0.1^{*}$ & 0.77 & 15 \\
\hline $1.1^{*}$ & 1.26 & 15 & 4.0 & 2.12 & 8 & $0.1^{*}$ & 0.77 & 15 \\
\hline $1.0^{*}$ & 1.26 & 15 & 3.2 & 1.92 & 8 & $0.3^{*}$ & 0.89 & 15 \\
\hline $1.8 *$ & 1.52 & 15 & $0.3^{*}$ & 1.87 & 15 & $0^{*}$ & 0.71 & 15 \\
\hline $\begin{array}{c}\text { 平均数 } \\
3.1\end{array}$ & 1.86 & 7.9 & 3.3 & 2.00 & 7.2 & 2.2 & 1.52 & 9. \\
\hline
\end{tabular}

* 感染后 15 日被杀死。 $x$ 肺部損伤程度。 $T$ 感染后存 活日数。

肺部損伤程度变异数分析

\begin{tabular}{|c|c|c|c|c|}
\hline 变异来源 & 平方 合 & 自由度 & 均方 & $F$ \\
\hline 总变 异 & 3.755 & 29 & & \\
\hline 处 理 & 1.204 & 2 & 0.602 & 6.38 \\
\hline 誤美 & 2.551 & 27 & 0.095 & \\
\hline
\end{tabular}

$n_{\mathrm{t}}=2, n_{2}=27, P<<0.01$, 差异十分显著。

两平均数之間的显著差开在 $P=0.05$ 时, 是 $2.052 \sqrt{\frac{2 \times 0.095}{10}}=0.28, P=0.02$ 时, 是 0.34 。与对照組相比, 第 3 組差异十分显渚，第 2 組差异不显著。

存活日数变异数分析

\begin{tabular}{|c|c|c|c|c|}
\hline 变异来源 & 平方合 & 自由度 & 均方 & $F$ \\
\hline 总变异 & 578.8 & 29 & & \\
\hline 处 理 & 27.8 & 2 & 13.90 & 1.47 \\
\hline 誤吉 & 551.0 & 27 & 20.41 & \\
\hline
\end{tabular}

$n_{1}=27, n_{2}=2, P>0.05$, 差异不显著。

两本均数之間的显㫪差异 $=2.052 \sqrt{\frac{2 \times 20.41}{10}}=4.1$ 天 第 2 組和第 3 組与对照組比較, 美异不显蓄。 


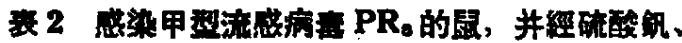
氯化络处理。肺部損伤程度

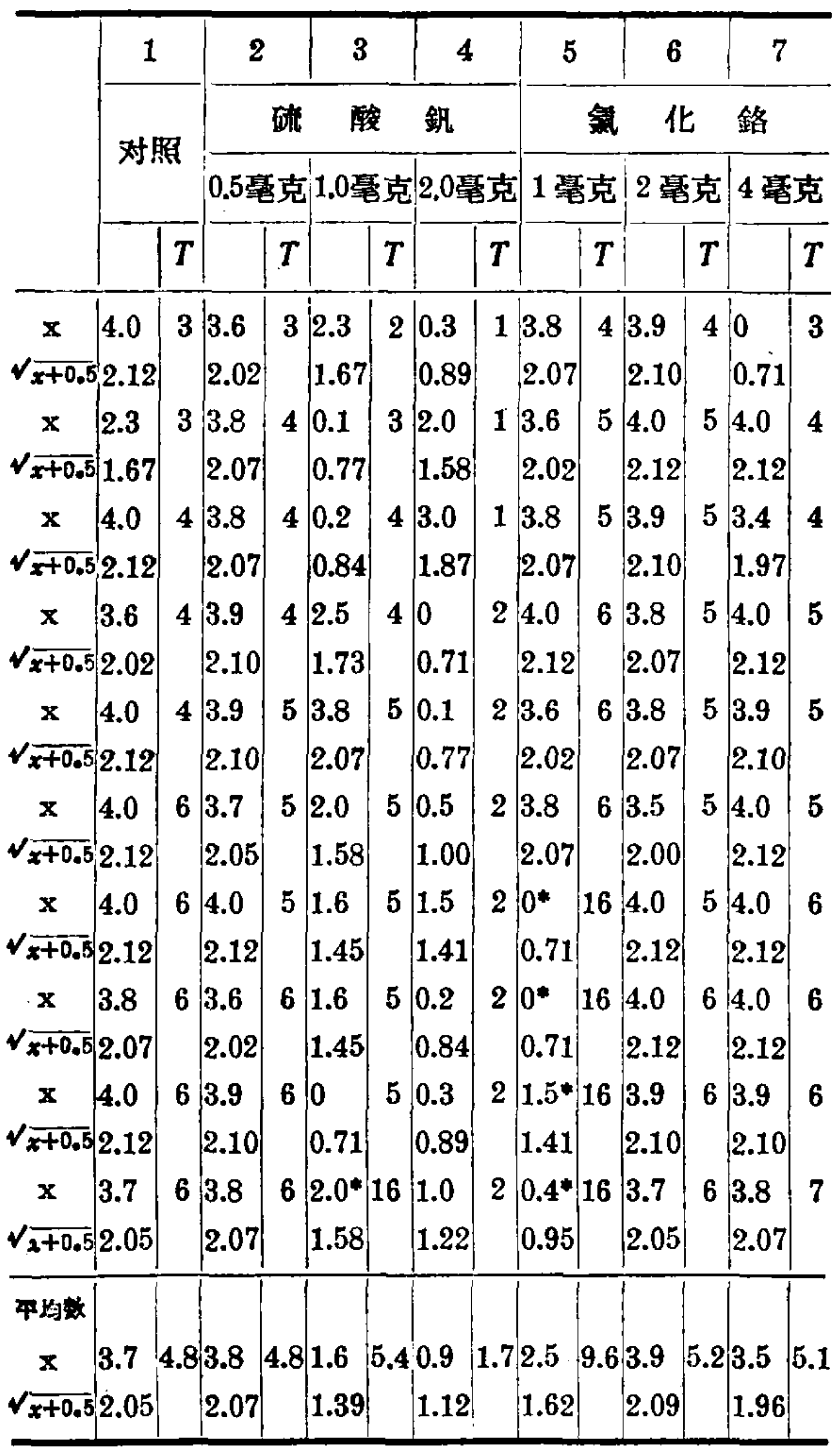

- 感染以后 16 日被杀死。 $x$, 肺部提伤程度。 $T$, 感染 后平均存活日数。

肺部損伤程度变异数分析

\begin{tabular}{|c|c|c|c|c|}
\hline 变异来源 & 本方合 & 自由度 & 均 方 & $F$ \\
\hline 总 变 开 & 17.869 & 69 & & \\
\hline 处 理 & 9.004 & 6 & 1.501 & 10.65 \\
\hline 酤美 & 8.865 & 63 & 0.141 & \\
\hline
\end{tabular}

$n_{1}=6, n_{2}=63, P>>0.01$, 有显著差异。在 $P=0.05$ 时, 两 平均数之間的显著差异为 $2.0 \sqrt{2 \times 0.141 / 10}=0.34$

当 $P=0.001$ 时, 为 0.58

与对照組相比，第 $3 、 4 、 5$ 組有显著美异。

存活日数变异数分析

\begin{tabular}{|c|c|c|c|c|}
\hline 变异来源 & 平方合 & 自由度 & 均 & $\mathrm{F}$ \\
\hline 总变异数 & 774.34 & 69 & \multirow[b]{2}{*}{53.291} & \multirow{3}{*}{7.39} \\
\hline 理 & 319.74 & 6 & & \\
\hline 差 & 454.60 & 63 & 7.216 & \\
\hline
\end{tabular}

$n_{1}=6, n_{2}=63, P<<0.01$ 。 当 $P=0.05$ 时, 两平均数 間的显著差昗为 $2.0 \sqrt{2 \times 7.216 / 10}=2.4$ 天

当 $P=0.001$ 时, 为 4.2 天

与对照組相比, 第 5 租有显登差异。
些。也可能所得到的結果更好过两种单独处理的说

和, 这种情况是很重要的。

承閻佩理同志在技术操作上予以协助，謹此志謝。

$$
\text { 王 善 源 }
$$

（中国医学科学院流行族研究所） 1958 年 3 月 22 日

[1] 王善源，某些元素对流行性感目族毒的㧕制作用 I.II III. IV., 科学通报，1958 年第5 期，157-159 頁， 第 6 期，188-189 頁; 第 7期, 215-218頁，第 8 期， 246-248 頁。

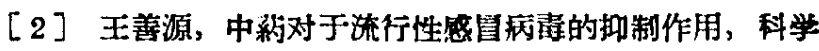
通报，1958 年第 3 期，90-91 頁。

\section{关于麻疹病毒分离的研究}


物, 关于麻疹病原的研究直至四年前由 Enders 和 Peebles (2) 利用組織培养分离腋惨病毒犾得成功以后 才有比較迅速的發展。䝮疹在我国目前仍为危害兒童 健康最严重的传染病, 为了配合防治工作, 在过去一 年中我們做了些研究，扞获得了病表一株，茲将經过 簡报如次。

1957 年春当㒋疹在北京流行很厉害的时候，从 14 个典型病例中"，我們采集了 10 份喉拭子和 6 份血 液标本，进行了組糡培养和传代。結果，10 份喉拭子 全屬㓌性; 6 份血液标本, 1 例可疑 (鹃 8-a), 1 例为 陽性（麻 9-a)。

在麻 8-a 标本的第 3 代胎兒組織細胞內，我何看 到了病变，但在后来的几代糍縜传代中得不到竐:笑， 故定其結果为可疑。

标本麻 9-a原始（第一代）培养是在单層猴腎細 胞管內做的，但自第二代起即改用人胎腎組織塊。就 在这第二代的組織內我們發現病变，表示病責的存 在。当时将第二代培养管在旋轉政上（每小时痰轉12 次） $36^{\circ} \mathrm{C}$ 培养 12 天之后，即把管內液体取出，置 $-40^{\circ} \mathrm{C}$ 低濫保存, 而将組織用 $10 \%$ 的蚁醛固定, 染色 作片保存。三个牛月后鏡检时始發現典型病变，当即 将保存于低温中的麻 9-a 培养液取出，重新接种于胎 督組織管內(第三代)。在第三代以及以后繼䋶传代的 20 代培羌中，每代都遇見到如同在第二代所看到的病 变, 而且随传遞次数的增加，病变更为明显。

所謂細胞病变包括三重点：空泡或泡沫状态的形 成，骶合多核巨細胞之出現和病变区域內細胞核內的 变化。

空泡或泡沫病变, 極其明显, 用佂倍鏡 $(60 \times)$

* 承北京市兒童医院諸福栄院长和柱淑明主任协助，镆 此致謝。 